\title{
Type of Music on the Growth and Laying Performance, Behavior and Marketability of Quails
}

\author{
Nora Cabaral $^{1 *}$, Hugo Untalan ${ }^{2}$, Prime Gilbert Rieta ${ }^{1}$ \\ ${ }^{1}$ State College of Agriculture and Technology, Philippines \\ ${ }^{2}$ Regulatory Division, Department of Agriculture, Philippines \\ *Corresponding author: Nora Cabaral: santosastrid22@gmail.com
}

\section{OPEN ACCESS}

Citation: Cabaral N., Untalan $\mathrm{H}_{\text {., }}$ Rieta P.G. (2017) Type of Music on the Growth and Laying

Performance, Behaviour and Marketability of Quails. Open Science Journal 2(4)

Received: $3^{\text {rd }}$ June 2017

Accepted: $1^{\text {st }}$ September 2017

Published: $13^{\text {th }}$ Dece,ber 2017

Copyright: (C) 2016 This is an open access article under the terms of the Creative Commons

Attribution License, which permits unrestricted use, distribution, and reproduction in any medium, provided the original author and source are credited.

Funding: The author(s) received no specific funding for this work

Competing Interests: The author have declared that no competing interests exists.

\section{Abstract:}

A study was conducted to determine how different type of music influences the performance, egg quality, behavior and economics of raising Japanese quails. A total of 165 sexed day-old chicks was randomly assigned to five treatments and replicated three times with eleven quails (10 females and 1 male) per replication and was conducted from August to November, 2016. All data were subjected to ANOVA following the CRD and differences between treatments were subjected to Tukey's Test. Analysis revealed that quails exposed with random music showed highly significant $(\mathrm{p}<0.05)$ final body weight, compared to quails provided with metallic, reggae and quails that was not provided with any kind of music but is similar with quails exposed with classical music. Quails exposed to random, metallic and reggae music had significantly higher $(\mathrm{p}<0.05) \%$ hen-day production and are more efficient in converting feeds into dozen of eggs. Quails exposed to random and classical music had significantly higher $(\mathrm{p}<0.05)$ egg white weight, fertility and hatchability rate and had thicker shell. However, results revealed comparable egg yolk weight and yolk color regardless of types of music. Results showed that quails exposed with reggae music significantly improved eating habit and are less aggressive compared to quails provided with metallic music and quails not subjected with any kind of music but are comparable with the eating habit and aggressiveness of quails exposed with random and classical music while provision of different type of music did not trigger chirping and feather pecking among Japanese quails. The EFPR, net income and ROI of quails subjected to random and classical music was significantly higher. These results implies that provision of random and classical music increases egg production and improved FCR that consequently increases profit than the normal management practices in quails reared without any exposure to music. 
Keywords: Random music, Classical music, Chirping, Egg quality, Eggfeed-price-ratio

\section{Introduction}

The Bureau of Animal Statistics (BAS, 2015) reported that quail comes third in the production of poultry products following ducks and broiler as the secondary and primary source, respectively. Despite being only third, quail raising in the country is promising. This can be started with a much lower capital investment as compared to chicken and ducks.

Raising quails is easy and less demanding. Quail are easy to raise and its housing requirement is not as complicated as that for chicken (Lambio, 2010; Capitan, 2003). Moreover, they are quick growers, fast multipliers and very efficient in converting feeds to egg and meat (Bolla and Randall, 2012). Quails, unlike other fowl, are not delicate birds and not easily be transmitted with various fowl diseases common to poultry, especially chickens (Mulemora, 2013). In addition, there is a growing demand for quail eggs and meat at present. In streets, stores, restaurants, hotels and bars, quail eggs and meat are in great demand. Aside from this quail eggs can be sold fresh, boiled, salted, pickled or as "balut". In addition, some reputable bakeries even use quail eggs as an ingredient in baking and in making leche-flan.

However, despite its advantages, quail raising in the Philippines cannot reach its full potential due to the birds sensitivity to noise stress that poses a reduction on weight and significant decrease in egg production. On the other hand, there are several researchers who mentioned that music enhances the auditory stimuli and response of the birds, helps cover up loud noises keeping the hens more relaxed in their environment and aids the quails to comfortably lay eggs and activate the hen's reproductive system, thus improving egg productivity. However, there are limited publications which reported that particular music improved egg production. Hence, this study was conducted to determine how various types of music influence the laying performance (including egg quantity and egg quality) and economics of quail production (Retallack, 2008; Morell, 2013; Ri et al., 2006; Lokuta, 2013; poultry hub, 2006).

The study was conducted to determine how various type of music influence the laying performance and economics of Japanese quail raising specifically, to determine the effect of types of music on the growth performance of quails in terms of average daily gain and final body weight; effect of types of music on the egg production in terms of percent hen-day production, feed consumption and feed conversion ratio per dozen eggs of Japanese quail; effect of types of music on the egg quality in terms of egg weight (egg yolk and albumen), yolk color, shell thickness and fertility rate of Japanese quail; effect of types of music on the on quail's behavior in terms of eating habit, chirping, feather pecking, aggressiveness; and economics of raising Japanese quail exposed to different type of music in terms of egg feed price ratio, net income and return on investment. 


\section{Materials and Methods}

\section{Materials}

A total of 165 sexed day-old chicks that was randomly assigned to five treatments were used in the study and was conducted from August to November, 2016. Quails were reared in grower and layer cages with sound proof material and equipped with drinking and feeding troughs and incandescent bulbs. Music players, speakers and weighing scale, record notebook and ballpen, calculator and decibel meter were also used in the conduct of the study.

\section{Methods}

Experimental Design and Treatments

The quails were randomly distributed into five treatments and were replicated three times with eleven quails (10 females and 1 male) per replication using the Completely Randomized Design (CRD).

The treatments are as follows:

Treatment 1 - Control (without music)

Treatment 2 - Random music

Treatment 3 - Classical music

Treatment 4 - Metal music

Treatment 5 - Reggae music

Birds in treatments 2, 3, 4, and 5 were subjected to non-stop music for 12 hours every day.

\section{Housing and Equipment Preparation}

There were 15 cages about 1 foot in length, 1 foot in width and 6 inches in height were used. All cages were placed at the same experimental area with a 5 meters distance from each cage. Before the arrival of the birds, the cages, drinking and feeding troughs and all other equipment used in the study were cleaned and disinfected thoroughly. Fifteen 10-watt bulbs were provided in the cages as source of heat and light. During brooding period, all treatment was provided 24 hours to provide proper temperature. Each cage under treatments 2, 3,4 , and 5 was provided with speaker as source of music.

\section{Music and Lighting Management}

To stimulate laying of quails at 6 weeks of age, each cage was provided with a light bulb (10 watts) that was turn on at 6:00pm and turn off at 9:00pm as source of heat and light. Cage under treatments $2,3,4$, and 5 were provided with speaker with memory card to provide the music based on the assigned treatment. Music was turned on during the start of feeding in the morning at 6:00 am and was turned off in the evening at 6:00 pm. All cages was provided with insulator 
as sound proofing material to make sure that music provided was directly heard by the experimental birds. The normal volume of 60 decibel using the decibel meter was maintained throughout the duration of the study.

\section{Feeds and Feeding}

Ad libitum feeding for birds in all treatments was practiced. At the start of the study, the quails were fed with starter ration. After brooding (15th day of the experiment), feed was gradually shifted to grower mash at the following ratios: 75 $\%$ starter and $25 \%$ grower mash on the first day of shifting $50 \%$ starter and 50 $\%$ grower mash on the second day of shifting $25 \%$ starter and $75 \%$ grower mash on the third day of shifting $100 \%$ grower mash on the fourth day of shifting until the end of the study. Gradual shifting was done for acclimation purposes and to prevent the possible occurrence of various digestive problems like diarrhea.

At the 6 th week of the experiment, feeds were gradually shifted to layer mash using the following scheme: $75 \%$ starter, $25 \%$ layer mash on the 1stday of shifting; $50 \%$ starter, $50 \%$ layer mash on the 2ndday of shifting; $25 \%$ starter, $75 \%$ layer mash on the 3rdday of shifting; 100\% layer mash on the 4thday of shifting until the end of the study. In addition, fresh and clean water were also given ad libitum.

\section{Care and Management}

Quails were subjected to uniform care and management except for the treatments applied (type of music per treatment) throughout the experimental period. In addition, proper sanitation and cleanliness of the cages and the surroundings was also maintained to prevent possible disease incidence.

\section{Statistical Analysis}

The data were subjected to Analysis of Variance (ANOVA) for the Completely Randomized Design (CRD). Significant differences between any two treatments was further determined through Tukey's Test using the SAS Software.

\section{Data Gathered}

\section{A. Body Weight and Body Weight Gain}

Weight of quails after brooding was considered as the initial body weight. This was done by randomly distributing ten quails per replication and was weighed to get the average. In addition, all quails were weighed after 70 days of rearing for the final body weight and it was done in the morning before feeding the birds. The average body weight at each weighing was determined by dividing 
the total body weight by the number of birds weighed. On the other hand, the body weight gain was calculated by subtracting initial weight from the final weight.

\section{B. Egg Production}

$\%$ Hen-day production

The average number of eggs produced by quails was determined by getting the ratio of the number of egg produced and the number of hens per replication the day the quails start laying eggs (i.e. 42 days). The $\%$ Hen-day production was computed using this formula:

$\%$ Hen-day production $=$ total \# of egg produced total \# of hens

x 100

\section{Feed Consumption}

Feed consumption was calculated by subtracting the amount of feed refused from the amount of feed offered per cage. Weighing of feed offered and feed refused was done daily. In addition, total and average feed consumption per replication was also gathered.

\section{Feed Conversion Ratio}

Feed conversion ratio was obtained after 40 to 70 days of rearing. This was calculated by dividing the feed consumption (total feed consumed divide to the number of quails per replication) by the by the dozen of egg.

\section{B. Egg Quality}

The characteristics such as egg yolk weight, egg white weight, egg yolk color using the 16 blades yolk color fan and egg shell thickness of eggs laid by quails subjected to different types of music was also determined. All eggs laid every 7th day (weekly basis) of the experiment period were undergone egg quality test.

\section{Fertility Rate}

All egg collected at 5st to 6 th week was placed in the automatic incubator and candled at 7 th day of incubation for fertility test. Fertility rate was calculated by dividing the number of fertile eggs by the total number of eggs set in the incubator multiplied by 100 the formula was presented below. 


\section{Fertility rate $=\quad$ total number of fertile eggs $\times 100$ number of eggs set in the incubator}

\section{Hatchability Rate}

All fertile eggs remain in the automatic incubator for hatching. Hatchability rate was calculated by dividing the number of hatches by the total number of fertile eggs in the incubator multiplied by 100 . The formula was presented below.

Hatachbaility rate $=$ Total number of hatches $x 100$

No. of fertile eggs in the incubator

\section{Behavior}

Behavior of female quails was evaluated twice a day (7 am and $5 \mathrm{pm}$ ) from growing to laying period (42 to 70 days). The behavior was observed and recorded based on 3-hedonic scale as follows:

Eating habit

3- Very often (90\% are eating)

2- Often (70-80\% are eating)

1- Sometimes (30-50\% are eating)

Chirping

3 - Very often (90\% are chirping )

2 - Often (70-80\% are chirping)

1 - Sometimes (30-50\% are chirping )

Feather pecking

3 - Very often (90\% are pecking feather)

2 - Often (70-80\% are pecking feather)

1 - Sometimes (30-50\% are pecking feather)

Aggressiveness

3 - Very aggressive (90\% are aggressive)

2 - Aggressive (70-80\% are aggressive)

1 - Inactive (30-50\% are aggressive)

\section{E. Economic}

\section{Egg Feed Price Ratio}

EFPR is the ratio between the receipts from egg and expenditure on feed.

This was computed using the formula below:

$\boldsymbol{E F P R}=$ Total value of egg produced

Total value of feed consumed 


\section{Cost and Return}

The cost of producing quails using various type of music was recorded. Net income and return on investment was computed using the following formulas:

Net Income $=$ Total Sales - Total Expenses

$$
\boldsymbol{R O I}=\frac{\text { Net income }}{\text { Total Expenses }}
$$

\section{Result and Discussion}

The different parameters evaluated in the performance of Japanese quails during the growing and laying period including initial and final bodyweight, weight gain and average daily gain, \% hen-day production, feed consumption, feed conversion ratio (FCR), egg weight, yolk color, shell thickness, fertility and hatchability rate are presented in Table 1,2 and 3. Furthermore, data for the behavior and economic in terms of eating habit, feather pecking, aggressiveness, chirping, egg feed price ratio (EFPR), net income, and return on investment was shown in Table 4 and 5.

\section{Body Weight}

Results revealed similar $(\mathrm{P}>0.05)$ initial body weight among Japanese quails used in the experiment (Table 1). On the other hand, analysis on the final body weight, weight gain and average daily gain showed significant differences among treatments. Quails provided with random or classical music showed significantly higher $(\mathrm{p}<0.05)$ final body weight, compared to quails provided with metallic, reggae and quails that was not provided with any kind of music.

The results imply that random or classical music significantly produced heavier quails than the other treatments. Results can be probably due to the favorable effect of random or classical music on the auditory and physical enrichment that increases tolerance to fear and stress of the quails (Davilla et al., 2011; Campo and Gil, 2004). Moreover, Leeds (2010) emphasized that auditory inputs like music have impacts on the body pulses like in brain waves, heart rate and breathing. The said body pulses were relative to the moods and habit which affects the birds feed intake. These results also confirm the statement of Hopkins (2000) that music can trigger eating habits.

\section{Egg Production}

\section{a.Percentage hen-day production}

The average number of eggs produced by quails was determined by getting the ratio of the number of egg produced and the number of hens per replication the day the quails start laying eggs (i.e. 42 days). Results revealed significant 
$(\mathrm{P}<0.05)$ differences in the \%hen-day production of Japanese quails used in the experiment (Table 2). Moreover, quails exposed to random, metallic and reggae music had significantly higher $(\mathrm{p}<0.05)$ percentage hen-day production with $88 \%$, $86.67 \%$ and $82.67 \%$, respectively compared to quails exposed to classical music $(79.33 \%)$ and quails not exposed to any kind of music $(74.67 \%)$.

Results can be probably due to the favorable effect of random, metallic and reggae music on the auditory and physical enrichment that increases tolerance to fear and stress of the quails (Davilla et al., 2011; Campo et al., 2005). In addition, background music helps cover up loud noises keeping the hens more relaxed in their environment (Milanians, 2015; Retallack, 2008) which helps the quails to comfortably lay eggs and activated the hen's reproductive system and made them lay more eggs. However, this result is in contrast with the findings of Campo and Gil (2004) which states that specific noise or music sounds immobilize laying of hens.

On the other hand, lower egg production observed in quails exposed to classical music and quails not exposed to any kind of music may be attributed to their highest feed intake (Table 2).

\section{b. Feed Consumption}

Results in Table 2 shows the feed consumption of quails exposed to different types of music. Based on the analysis, quails provided with random, metallic and reggae music had significantly lower $(\mathrm{p}<0.05)$ feed consumption compared to quails exposed to classical music and quails not exposed to any kind of music.

These results were in line with the findings of Miclaus (2011), Christoper (2011), Patricelli and Blickley (2006), and Wissman (2015) who mentioned that classical music results to regular eating and resting for a longer period of times without excessive movement which eventually lengthens the meal duration and more feed intake which has similar principle in quails not exposed to any kind of music and noise. Similarly, Davila et al., (2011) reported that layers provided with classical music reduces stress due to auditory enrichments, thus improves feed intake.

Table 1. Body weight, weight gain and average daily gain of Japanese quails raised under different type of music

\begin{tabular}{llc}
\hline \hline TYPE OF MUSIC & IBW & FBW \\
\hline No music & $51.60^{\mathrm{a}}$ & $455.10^{\mathrm{b}}$ \\
Random music & $52.13^{\mathrm{a}}$ & $516.63^{\mathrm{a}}$ \\
Classical music & $51.83^{\mathrm{a}}$ & $496.60^{\mathrm{a}}$ \\
Metallic music & $52.07^{\mathrm{a}}$ & $470.47^{\mathrm{b}}$ \\
Reggae music & $51.50^{\mathrm{a}}$ & $472.53^{\mathrm{b}}$ \\
\hline \hline
\end{tabular}

Legend: Means within column with different superscript are significantly different $(\mathrm{P}<0.05)$; IBW-initial body weight; FBW - final body weight

\section{c. Feed Conversion Ratio}


Feed conversion ratio (FCR) was determined based on the amount of feeds needed to produce a dozen of eggs. The FCR of Japanese quails exposed to different types of music were also presented in Table 2. Analysis revealed that the feed conversion ratio of quails exposed to random, metallic and reggae music are more efficient $(\mathrm{p}<0.05)$ in converting feeds into dozen of eggs compared to quails exposed to classical and quails not exposed to any kind of music.

There is no direct study regarding the effect of specific kind of music on the feed conversion ratio in terms of egg production of quails. However, results can be associated with the higher \% hen-day production of quails provided with random, metallic and reggae music.

Table 2. Percentage hen-day production of Japanese quails raised under different type of music

\begin{tabular}{llll}
\hline \hline TYPE OF MUSIC & \% hen-day production & FC/day & FCR/dozen of egg \\
\hline No music & $74.67^{\mathrm{b}}$ & $306.30^{\mathrm{a}}$ & $334.15^{\mathrm{a}}$ \\
Random & $88.00^{\mathrm{a}}$ & $259.07^{\mathrm{b}}$ & $282.62^{\mathrm{b}}$ \\
Classical & $79.33^{\mathrm{b}}$ & $280.21^{\mathrm{a}}$ & $305.68^{\mathrm{a}}$ \\
Metallic & $86.67^{\mathrm{a}}$ & $263.91^{\mathrm{b}}$ & $288.81^{\mathrm{b}}$ \\
Reggae & $82.67^{\mathrm{a}}$ & $261.93^{\mathrm{b}}$ & $286.65^{\mathrm{b}}$ \\
\hline \hline
\end{tabular}

Legend: Means within column with different superscripts are significantly different $(\mathrm{P}<0.05)$; FC - feed consumption; FCR - feed conversion ratio

\section{Egg Quality}

\section{a.Fertility and Hatchability Rate}

Results revealed significant $(\mathrm{p}<0.05)$ differences in the fertility and hatchability rate of Japanese quails exposed to different type of music. Additionally, quails exposed to random and classical music had significantly higher $(\mathrm{p}<0.05)$ fertility rate of $87.30 \%$ and $81.74 \%$; and hatchability rate of $92.19 \%$ and $91.73 \%$, respectively compared to quails provided with metallic and reggae music and quails not exposed to any kind of music.

There is no direct study regarding the effect of specific kind of music on the fertility and hatchability rate. However, this can be associated to the thicker shell and higher egg white weight of quails exposed to random and classical music (Table 3). In addition, favorable background music helps like classical music cover up loud noises keeping the hens more relaxed in their environment (Milanians, 2015; Retallack, 2008) which helps the quails to comfortably lay eggs and activated the hen's reproductive system and made them lay eggs with thicker shell.

\section{b.Egg Yolk and Egg White Weight}

The egg yolk and egg white weight of the eggs laid by the quails exposed to different types of music were also presented in Table 3. Results revealed comparable $(\mathrm{p}>0.05)$ egg yolk weight but significant differences $(\mathrm{p}<0.05)$ was 
observed in the egg white weight of Japanese quails exposed to various types of music (Table 3). Results were similar with the findings of Morell (2013) that music, particularly classical music, enhances the egg weight as it was tested in the laying hens. In addition, higher egg white weight of quails exposed to random music can be associated to the favorable effect of random music on the auditory and physical enrichment that increases tolerance to fear and stress of the quails (Davilla et al., 2011; Campo et al., 2005).

\section{c.Egg Shell Thickness}

The egg shell thickness of the eggs laid by the Japanese quails exposed to different types of music was also presented in Table 3. Analysis found out that the egg shell thickness of Japanese quails exposed to random and classical music had thicker shell $(\mathrm{p}<0.05)$ compared to quails provided with metallic, reggae music and quails not exposed to any kind of music.

There is no direct study regarding the effect of specific kind of music on the egg shell thickness.

\section{d.Egg Yolk Color}

Analysis revealed comparable $(\mathrm{p}>0.05)$ egg yolk color of Japanese quails exposed to various types of music and quails not exposed to any kind of music (Table 3). Results may be due to uniform feeding management throughout the period of the study and may imply that provision of music did not trigger higher nutrient absorption.

\section{Behavior}

\section{a. Eating habit}

Results revealed significant $(\mathrm{p}<0.05)$ differences on the eating habit of Japanese quails used in the experiment (Table 4). Moreover, quails exposed with reggae music had significantly $(\mathrm{p}<0.05)$ performed heartily eating behavior compared to quails provided with metallic music and quails not subjected with any kind of music but are comparable with the eating habit of quails exposed with random and classical music.

Table 3. Egg quality of Japanese quails exposed with different type of music.

\begin{tabular}{lllllll}
\hline \hline TREATMENT & FR $(\%)$ & HR $(\%)$ & EYWT $(\mathrm{g})$ & EWWT $(\mathrm{g})$ & EST $(\mathbf{m m})$ & EYC \\
\hline No music & $74.86^{\mathrm{b}}$ & $86.83^{\mathrm{b}}$ & $3.00^{\mathrm{a}}$ & $5.00^{\mathrm{b}}$ & $0.26^{\mathrm{b}}$ & $8.67^{\mathrm{a}}$ \\
Random music & $87.30^{\mathrm{a}}$ & $92.19^{\mathrm{a}}$ & $3.67^{\mathrm{a}}$ & $7.33^{\mathrm{a}}$ & $0.31^{\mathrm{a}}$ & $9.00^{\mathrm{a}}$ \\
Classical music & $81.74^{\mathrm{a}}$ & $91.73^{\mathrm{a}}$ & $3.67^{\mathrm{a}}$ & $6.67^{\mathrm{a}}$ & $0.34^{\mathrm{a}}$ & $9.00^{\mathrm{a}}$ \\
Metallic music & $77.71^{\mathrm{b}}$ & $87.66^{\mathrm{b}}$ & $3.33^{\mathrm{a}}$ & $5.33^{\mathrm{b}}$ & $0.28^{\mathrm{b}}$ & $9.00^{\mathrm{a}}$ \\
Reggae music & $76.34^{\mathrm{b}}$ & $87.18^{\mathrm{b}}$ & $4.00^{\mathrm{a}}$ & $5.67^{\mathrm{b}}$ & $0.29^{\mathrm{b}}$ & $9.67^{\mathrm{a}}$ \\
\hline \hline
\end{tabular}


Increase feed intake of quails after exposure to reggae, random and classical music can be attributed to the uplifting effect of above music that the birds may possibly like to eat well. This outcome confirms the statement of Lokuta (2013) that exposure to background music while eating helps poultry species to enhance their meal duration and feed intake.

In addition, results was in line with the findings of Wissman (2015) who mentioned that music results to regular eating and resting for a longer period of times without excessive movement which eventually lengthens the meal duration and more feed intake. Similarly, Davila et al., (2011) and Campo et al., (2005) reported that layers provided with reggae music reduces stress due to auditory and physical enrichment that increases tolerance to fear and stress of the quails, thus improves feed intake.

On the other hand, lower scale on the eating behavior of quails exposed to metallic music can be associated with the principle discussed by Campo and Gil (2004) that loud noise and blared music sounds immobilizes eating and laying of hens. This statement was in contrast to the findings discussed by Milanians (2015) and Retallack (2008) who reported that any background music helps cover up loud noises keeping the hens more relaxed in their environment which helps them to comfortably eat and lay eggs.

Table 4. Behavior of Japanese quails raised under different type of music

\begin{tabular}{lcccc}
\hline \hline TREATMENT & $\begin{array}{c}\text { EATING } \\
\text { HABIT }\end{array}$ & $\begin{array}{c}\text { FEATHER } \\
\text { PECKING }\end{array}$ & AGGRESSIVENESS & CHIRPING \\
\hline No music & $1.53^{\mathrm{b}}$ & $2.00^{\mathrm{a}}$ & $1.56^{\mathrm{a}}$ & $1.99^{\mathrm{a}}$ \\
Random music & $1.70^{\mathrm{a}}$ & $1.94^{\mathrm{a}}$ & $1.33^{\mathrm{b}}$ & $1.89^{\mathrm{a}}$ \\
Classical music & $1.68^{\mathrm{a}}$ & $1.94^{\mathrm{a}}$ & $1.32^{\mathrm{b}}$ & $1.89^{\mathrm{a}}$ \\
Metallic music & $1.57^{\mathrm{b}}$ & $1.99^{\mathrm{a}}$ & $1.50^{\mathrm{a}}$ & $1.91^{\mathrm{a}}$ \\
Reggae music & $1.82^{\mathrm{a}}$ & $1.94^{\mathrm{a}}$ & $1.32^{\mathrm{b}}$ & $1.86^{\mathrm{a}}$ \\
\hline \hline
\end{tabular}

\section{b. Feather pecking}

Feather pecking in poultry is one of the major constraints why poultry industry cannot reach its full potential in terms of egg and meat production, as it may lead to feather damage, injuries and eventually mortality (Alworth and Buerkle, 2013; Stein, 2009; Bourns, 2008; and Krimpen et al., 2005).

Feather pecking, especially the severe type, negatively affects the welfare and behaviour of quail (Blokhuis and Arkes, 1984). This damaging behavior is painful for quail, it can also lead to cannibalism and death, and therefore, a significant animal welfare issue. Moreover, feather pecking is thought to be a redirected foraging behavior rather than a form of aggression, and may be due to the quail mistaken perception of feathers as an appropriate foraging substrate (Riber et al., 2007).

Analysis revealed comparable $(\mathrm{p}>0.05)$ scale on the feather pecking of Japanese quails exposed with various types of music and quails not expose with any kind of music (Table 4). This result implies that the different type of music did not trigger feather pecking behavior among Japanese quails. 


\section{c. Aggressiveness}

Results revealed significant $(\mathrm{p}<0.05)$ differences on the aggressiveness of Japanese quails used in the experiment (Table 4). Moreover, quails exposed with metallic music and quails not exposed to any kind of music showed more aggressive birds $(\mathrm{P}<0.05)$ compared to quails exposed with random, classical and reggae music where lesser aggression were occurred and observed.

Results imply that under natural circumstance where quails are reared without provision of music, the aggressive behavior of birds normally arouses. However, when quails were exposed to harsh and blared noise like metallic music, aggressiveness was also triggered and observed.

There is no direct study regarding the effect of specific kind of music on the aggressiveness among quails. However, aggressiveness of the birds exposed with metallic music may be attributed to the claim that grunge music like metallic music increases fatigue, tension, sadness and hostility, as well as decreased mental clarity, vigor, relaxation and compassion in human (Rowe, 2010). This statement was supported by Linn (2000) and Alworth and Buerkle (2013) that exposure with harsh music sound affects animals (i.e. laboratory animals, livestock) similarly to humans in terms of physiology, cognition, brain chemistry and behavior.

Results also confirmed the findings of Estlund (2005) who reported that more hostile, aggressive or angry behavior of laboratory animals can be recognized after exposure to heavy metallic music.

On the other hand, the lesser aggression observed among quails exposed with random, classical music and reggae music may be associated to the statement of Liberty (2005) and Wells (2002) who mentioned that the above specified type of music significantly diminished agitation, improve moods and lower levels of stress. The results also confirmed that classical music and other similar soft sound like reggae music indeed reduces aggression of birds (poultryhub, 2006).

\section{d. Chirping}

Chirping is a short, sharp, high-pitched sound made by small birds like Japanese quails. It was considered one way of bird's communication and was often observed during mating period.

Analysis revealed comparable $(\mathrm{p}>0.05)$ chirping behavior among Japanese quails regardless of different type of music exposure. This means that different type of music did not trigger chirping behaviour among quails. Results were similar to the findings of Linn (2000) that provisions of any kind of music have no significant effect on the chirping behavior in quails.

\section{Economics}

\section{a.Egg-Feed Price Ratio (EFPR)}

Egg-feed price ratio is used to indicate the relative profitability of egg production obtained by studying the relationship between egg prices and the cost 
of feed (Yorke, 1949). This is calculated by dividing the total value of egg produced over total value of feed consumed.

As shown in Table 5, the EFPR of Japanese quails exposed to different types of music had significantly higher $(\mathrm{p}<0.05)$ EFPR compared to quails not exposed to any kind of music.

Results can be attributed to the significantly higher $(\mathrm{p}<0.05)$ egg production (i.e. \% hen-day production), lower feed consumption and more efficient FCR of quails exposed to different types of music. These findings was in line with Wissman (2015), Roque (2013), Davilla et al., (2011), Leeds (2010), Worldpoultry (2008), Liberty (2005) and Hopkins (2000) who reported that provision of music improved egg production and eventually improved the feed conversion efficiency compared to the normal management practices in quails reared without any provision of music.

\section{b.Return on Investment}

The cost of producing quails using various type of music was recorded. Net income and return on investment was also computed and was presented in Table 5. In general, analysis revealed that quails exposed to random and metallic music has the highest incurred net income and return on investment that was significantly higher $(\mathrm{p}<0.05)$ from quails exposed to classical and quails not exposed to any kind of music but are comparable $(\mathrm{p}>0.05)$ to quails provided with reggae music.

The lower value of net income and return on investment of quails exposed to classical music and quails not provided with any kind of music can be attributed to their higher feed intake which eventually increases total cost.

Table 5. Economics of producing Japanese quails exposed with different type of music

\begin{tabular}{|c|c|c|c|c|c|}
\hline TREATMENT & TS & $\mathbf{T C}$ & EFPR & NI & ROI \\
\hline T1 - No music & 949.60 & 788.86 & $3.71^{\mathrm{b}}$ & $160.74^{\mathrm{c}}$ & $20.39^{\mathrm{c}}$ \\
\hline T2 - Random music & 1119.80 & 868.92 & $5.48^{\mathrm{a}}$ & $250.88^{\mathrm{a}}$ & $28.91^{\mathrm{a}}$ \\
\hline T3 - Classical music & 1065.20 & 861.51 & $5.05^{\mathrm{a}}$ & $203.69^{b}$ & $23.64^{\mathrm{b}}$ \\
\hline T4 - Metallic music & 1111.40 & 881.17 & $4.14^{\mathrm{a}}$ & $230.24^{\mathrm{a}}$ & $26.11^{\mathrm{a}}$ \\
\hline T5 - Reggae music & 1085.20 & 865.59 & $4.04^{\mathrm{a}}$ & $219.61^{\mathrm{b}}$ & $25.38^{\mathrm{ab}}$ \\
\hline
\end{tabular}

\section{Conclusion}

The study revealed that classical and random music significantly improved final body weight, average daily gain and weight gain. In addition, random, metallic and reggae music improves egg production in terms of \%hen-day production and FCR per dozen of egg; egg quality in terms of fertility and hatchability rate, egg weight and egg shell thickness and improve the economics in terms of egg-feed price ratio, net income and return on investment. On the 
other hand, the study revealed that exposure to music does not significantly improve egg yolk weight and egg yolk color.

Results found out that quails exposed with reggae music significantly improved eating habit and are less aggressive compared to quails provided with metallic music and quails not subjected with any kind of music but are comparable with the eating habit and aggressiveness of quails exposed with random and classical music. On the other hand, analysis revealed that provision of different type of music did not trigger chirping and feather pecking behavior among Japanese quails.

\section{Recommendation}

Base on the study, the researchers recommend the use of classical and random music since it enhances the increase in body weight gain. In terms of egg production and FCR, the researchers recommend the use of random, metallic and reggae music since it enhances the auditory and physical enrichment that increases tolerance to fear and stress of the quails thus laid more eggs. In terms of egg quality, the researchers recommend the use of random and classical music since it increases the fertility rate that can be associated to the thicker egg shell that protects it from any foreign materials and contamination that may improve the quality of eggs during the incubation period.

Based on the result of the study, the researchers recommend the use of random, classical and reggae music since it enhances the eating habit while lessens the aggression of birds. Based on EFPR and ROI in terms of improving the productivity of Japanese quail, the researchers recommend to farmers exposing the quails to music either random, reggae, metallic or classical.

\section{Acknowledgment}

The authors wishes to give thanks to the following: Dr. Jesse T. Zamora, the Mindoro State College of Agriculture and Technology (MinSCAT) president for his encouragement to faculty researchers making their aspirations a reality and for the publication support; to all our students for the cooperation and hardwork; and our family, for the inspiration and untiring understanding, support and love.

\section{References:}

$\begin{array}{lllll}\text { Bureau of } & \text { animal } & \text { (2015). } & \text { Retrieved }\end{array}$ http://www.bai.da.gov.ph/phocadownload/publications/Phil-FarmAnimal_Atlas.pdf.

Lambio, A.L. (2010). Poultry Production in the Tropics. University of the Philippines, Los Banos, Laguna.

Capitan, S. (2003).The science and practice of quail production.CA Publication Office University of the Philippines Los Baños College, Laguna 4031 Philippines.

Capitan, S. (2012). The science and practice of quail production.CA Publication Office University of the Philippines Los Baños College, Laguna 4031 Philippines. 
Bolla, G. AND Randall, M. (2012). Raising Japanese quail. Retrieved July 17, 2013 from http://www.dpi.nsw.gov.au/_data/ assets/pdf_file/ 0005/145346/Raising- Japanese- quail.pdf.

Mulelora, H.A. (2013). Quail bird farming. Retrived July 20, 2013 from http://pmnewsnigeria.com/2013/03/28/quail-eggs-a-super-healing-food/

Retallack, S. (2008).Music used to calm poultry flocks. Retrieved August 23, 2014 from Retrieved August 23, 2014 from http://www.couriermail.com.au/news/

Morell, V. (2001).Birds found using human musical scales for the first time. Retrieved November 03, 2001 from http://news.sciencemag.org/biology/2001/11/birds- found-using-human-musical-scalesfirst-time.

RI, E., Sato,K., Oikawa, T., Kunieda, T.,Uchida,H. (2005). Effects of dietary protein levels on production and characteristics of Japanese quail eggs. J. Poultry Sci.42, 130- 139.

Lokuta, A. (2013). You're eating habits: the surprising details that make a difference. Retrived February 12, 2015 from http://www.mindthesciencegap.org/2013/03/29/ your-eating-habits-thesurprising-details-that-make-a-difference/.

Poultry Hub. (2006). Sounds and hearing of birds. Retrieved December 03, 2014 from http://www.poultryhub.org/production/husbandry-management/poultry behaviour/

Davila, S.G., J.L., Campo, M.G. Gil., M.T. Prieto AND O. Torres.(2011).Effects of auditory and physical enrichment on 3 measurements of fear and stress (tonic immobility duration, heterophil to lymphocyte ratio, and fluctuating asymmetry) in several breeds of layer chick.Poultry Science Association Inc.90:2459-2466 doi: 10.3382/ps.2011-01595

Campo, J.L. and Gil, M.G. (2004). Effects of specific noise and music stimuli on stress and fear levels of laying hens of several breeds. Retrieved February 05, 2015from:http://www.appliedanimalbehaviour. com/article/S0168-1591(04)00.216.

Leeds, J. (2010). The power of sound. Retrieved December 3, 2014 from http://thepowerof sound.net/animalresearch/.

Hopkins, J. (2000). Lose weight listening to music. Retrieved February 12,2015 from http://www.canadianliving.com /health/nutrition/lose_weight_listening_to_music.php.

Miclaus, C. (2011). Animals and Music. Retrieved December 03, 2014 from http://www.buzzle. com/articles/animals-and-music.html.

Chistoper, J. (2001). Effects of music on animals. Retrieved December 03, 2014 from http://pets. thenest.com/effects-listening-music-dogs-cats-5991.html.

Patricelli, G. L., and J. L. Blickley. (2006). Avian communication in urban noise: causes and consequences of vocal adjustment. The Auk 123:639-649.

Morell, V. (2013). Birds Found Using Human Musical Scales For The First Time. Retrieved from http//news.sciencemag.org/bilogy/2001/11/ birds-found-using-human-musical-scales-first-time.

Alworth, L.C., and Buerkle, S.C. (2013). The effects of music on animal physiology, behavior and welfare . Retrieved December 15, 2013 from http://www.ncbi.nlm.nih.gov/pubmed /23340788.

Stein, R. (2009).Study finds music may affect animals' moods. Retrieved December 15, 2013 from http://www.sfgate.com/nation/article/Study-finds-music-may-affect-animals-moods3217490.phpstory-fnihsrf21226820910760?nk $=5964251 \mathrm{e} 96 \mathrm{f5a} 5544 \mathrm{~d}$

Bourns, C. (2008). Poultry producers use music to calm their flocks. Retrieved August 23, 2014.Retrieved from http://www.fwi.co.uk/articles/11/09/2008/112029/poultry-producers-usemusic-to-calm-their-floc ks.html.

Jrowe, J. (2010). Does metal really have a negative effect on an animal's ability to learn? Retrieved March 16, 2015 from http://www.heavyblogisheavy.com/2010/03/24/does-metal-really-have-anegative-effect-on-an-animals-ability-to-learn/

Jestlund, S. (2005).The Effects of Music on Dogs. Retrieved from December 03, 2014 from http://www.ehow.com/list_5982275_effects-music-dogs.html.

Liberty, M. (2005). How does music affect an animal's behavior?. Retrived December 03, 2014 from http: //www.ehow.com/info_8652763_music-affect-animals- behavior.html.

Roque, A.L. (2013). The effects of auditory stimulation with music on heart rate variability in healthy women. Retrieved from February 17, 2015 from http://www.ncbi.nlm.nih.gov/ pmc/articles/PMC37 15016/.

World Poultry. (2008). Music helps raise quality chickens. Retrieved February 20, 2015 from http://www.worldpoultry.net/Breeders/ General/2008/8/Music-helps-raise-quality- chickensWP002861W/

Liberty, M. (2005). How Does Music Affect An Animal's Behavior?. Retrived December 03, 2014 Fromhttp://Www.Ehow.Com/Info_8652763_Music-Affect-Animals- Behavior.Html. 